\title{
Food balance sheet and household budget survey dietary data and mortality patterns in Europe
}

Androniki Naska ${ }^{1}$, Mari-Anna Berg ${ }^{2}$, Carmen Cuadrado $^{3}$, Heinz Freisling ${ }^{4}$, Kurt Gedrich ${ }^{5}$, Matej Gregorič ${ }^{6}$, Cecily Kelleher ${ }^{7}$, Emilia Leskova ${ }^{8}$, Michael Nelson ${ }^{9}$, Lucienne Pace ${ }^{10}$, Anne-Marie Remaut ${ }^{11}$, Sara Rodrigues ${ }^{12}$, Wlodzimierz Sekula ${ }^{13}$, Michael Sjöstrom ${ }^{14}$, Kerstin Trygg ${ }^{15}$, Aida Turrini ${ }^{16}$, Jean Luc Volatier ${ }^{17}$, Gabor Zajkas ${ }^{18}$, Antonia Trichopoulou ${ }^{1,19 *}$ and on behalf of Data Food Networking (DAFNE) participants $\dagger$

${ }^{1}$ Department of Hygiene and Epidemiology, School of Medicine, University of Athens, 75 Mikras Asias Street, Athens 115 27, Greece

${ }^{2}$ Statistics Finland, Helsinki, Finland

${ }^{3}$ Departamento de Nutrición, Facultad de Farmacia, Universidad Complutense de Madrid, Madrid, Spain

${ }^{4}$ Department of Nutritional Sciences, University of Vienna, Vienna, Austria

${ }^{5}$ Department of Marketing and Consumer Research, TUM Business School, Technische Universität München, Munich, Germany

${ }^{6}$ Department of Nutrition and Physical Activity, Health Promotion Centre, National Institute of Public Health of the Republic of Slovenia, Ljubljana, Slovenia

${ }^{7}$ National Nutrition Surveillance Centre, School of Public Health and Population Science, University College Dublin, Belfield,

Dublin, Republic of Ireland

${ }^{8}$ Department of Risk Assessment and Food Composition Data Bank, Food Research Institute, Bratislava, The Slovak Republic

${ }^{9}$ Division of Nutritional Sciences, King's College London, London, UK

${ }^{10}$ Health Promotion and Disease Prevention Department, Ministry of Health, Valletta, Malta

${ }^{11}$ Nutrition Unit, Faculty of Agricultural and Applied Biological Sciences, University of Gent, Gent, Belgium

${ }^{12}$ Faculdade de Ciências da Nutrição e Alimentação da Universidade do Porto, Porto, Portugal

${ }^{13}$ National Food and Nutrition Institute, Warsaw, Poland

${ }^{14}$ Unit for Preventive Nutrition, Department of Biosciences and Nutrition, Karolinska Institute, Stockholm, Sweden

${ }^{15}$ Department of Nutrition, Institute of Basic Medical Sciences, University of Oslo, PO Box 1046, Blinder, NO-0316 Oslo, Norway

${ }^{16}$ Unità di Statistica ed Economia Alimentare, Istituto Nazionale di Ricerca per gli Alimenti e la Nutrizione (INRAN), Rome, Italy

${ }^{17}$ French Food Safety Agency AFSSA, Paris, France

${ }^{18}$ National Institute of Food Safety and Nutrition, Budapest, Hungary

${ }^{19}$ Hellenic Health Foundation, Athens, Greece

(Received 1 April 2008 - Revised 4 September 2008 - Accepted 4 September 2008 - First published online 6 November 2008)

Worldwide dietary data for nutrition monitoring and surveillance are commonly derived from food balance sheets (FBS) and household budget surveys (HBS). We have compared food supply from FBS and food availability data from HBS among eighteen European countries and have estimated the extent to which they correlate, focusing on food groups which are comparably captured by FBS and HBS and for which there is epidemiological evidence that they can have a noticeable impact on population mortality. Spearman's correlation coefficient was $+0 \cdot 78\left(P<10^{-3}\right)$ for vegetables (including legumes $),+0.76\left(P<10^{-3}\right)$ for fruits, $+0.69\left(P<10^{-3}\right)$ for fish and seafood and $+0.93\left(P<10^{-3}\right)$ for olive oil. With respect to meat and meat products, the coefficient was lower at $+0.39(P=0.08)$. Moreover, we have examined whether the supply (FBS) or the availability (HBS) of food groups known or presumed to have beneficial effect on the occurrence of CHD and total cancer can predict overall, coronary and cancer mortality in ecological analyses. After controlling for purchasing power parity-adjusted gross domestic product and tobacco smoking we found that for vegetables, fruits, fish and seafood, as well as for olive oil, both the FBS and the HBS estimates were inversely associated with all three indicators of mortality, although the number of countries with complete information on all study variables hindered formal statistical documentation ( $P>0.05$ in some instances). FBS and HBS have their own strengths and weaknesses, but they may complement each other in dietary assessments at the population level.

Food balance sheets: Household budget surveys: Diet: DAFNE: Data Food Networking

Abbreviations: DAFNE, Data Food Networking; FBS, food balance sheet; GDP, gross domestic product; HBS, household budget survey.

$\dagger$ DAFNE participants: Austria, I. Elmadfa and A. Suchomel; Belgium, A. P. Cueto Eulert; Finland, A. Pajunen and T. Hirvonen; France, J. Maffre; Germany, G. Karg and K. Wagner; Greece, V. Bountziouka, Y Chloptsios, E. Oikonomou and K Tsiotas; Hungary, P. Szivos; Italy, S. Barcherini and S. Martines; Malta, E. Caruana and N. Camilleri; Norway, E. Mork and K. Lund-Iversen; Poland, A. Bienkuska, M. Morawska and Z. Niedzialek; Portugal, M. D. Vaz de Almeida; Republic of Ireland, S. Friel; Slovak Republic, H. Sukenikova; Slovenia, M. Gabrijelcic, M. Adamic and M. Remec; Spain, O. Moreiras, M. L. Boned and P. Seoane Spiegelberg; Sweden, E. Poortvliet; UK, D. Rimmer and S. Burr.

*Corresponding author: Dr Antonia Trichopoulou, fax +30 210746 2079, email antonia@nut.uoa.gr 
Dietary data for nutrition monitoring and surveillance can be derived from three main sources: food balance sheets (FBS), household budget surveys (HBS) and specifically designed individual nutrition surveys. The FAO-assembled FBS provide information on food supply at the population level, estimated on the basis of the annual food production, imports and exports, changes in stocks, agricultural and industrial uses within a country, as well as losses during storage and transportation $^{(1)}$. HBS are systematically conducted by National Statistical Offices in country-representative population samples and aim at collecting, among others, data on food availability at the household level ${ }^{(2)}$. Individual-based surveys, when participants' intakes are recorded as adequately as possible, provide the best evidence on food consumption and constitute the optimal method for assessing dietary patterns, evaluating diet-disease associations and quantifying determinants and consequences of food choices. Being expensive and labour intensive, however, representative individual-based surveys are undertaken regularly in only a limited number of countries, usually those with robust economies and years of experience in the field of dietary monitoring. Furthermore, differences in study design and data analysis reduce the comparability of results at an international level ${ }^{(3-6)}$.

Countries with no routine information on the food consumption of their population and those interested in comparing their national dietary patterns with those of other populations have traditionally used the FBS data which, in spite of their limitations, are often used to follow trends over time in the supply of food commodities at the population level and they have even been exploited for epidemiological research ${ }^{(7-10)}$. Like FBS, the HBS allow inter-country comparisons on a regular basis but, moving from total population to household level, they further allow the description of the current and developing structure of dietary patterns at national or regional level and of population subgroups defined on the basis of their sociodemographic characteristics ${ }^{(11-13)}$

In the present study, we have retrieved food supply data from the FBS and food availability data from the HBS of European countries in order to evaluate the extent to which they agree and to estimate the correlation between these dietary data and mortality statistics. Similar exercises have been undertaken in the past either with $\mathrm{FBS}^{(7-10)}$ or HBS $\operatorname{data}^{(11,14,15)}$.

\section{Methods}

Data from the following eighteen European countries were used, with calendar year of the HBS data collection in parentheses and FBS data referring to the first of the indicated years: Austria (1999-2000), Belgium (1987-8), Finland (1985), France (1985), Germany (1993), Greece (1987-8), Hungary (1991), Italy (1990), Malta (1994), Norway (1986-8), Poland (1988), Portugal (1989-90), Republic of Ireland (1988), Slovak Republic (1997), Slovenia (1998), Spain (1980), Sweden (1989) and the United Kingdom (1985). For each of these countries dietary data were retrieved for five main food groups (vegetables; legumes; fruits; meat and meat products; fish and seafood) and olive oil. Since the consumption of legumes is particularly low in some European countries, vegetables and legumes were combined in one food group. Data on the national supply of the aforementioned food groups expressed as $\mathrm{kg} /$ person per year were retrieved from FBS available online (http://faostat.fao.org/site/502/default. aspx) and were converted to $\mathrm{g} /$ person per $\mathrm{d}$. Data on food availability at the household level, expressed as g/person per $\mathrm{d}$, were retrieved from the Data Food Networking (DAFNE) databank, also available online (http://www.nut.uoa.gr/dafnesoftweb/).

The DAFNE databank, developed with European Commission support, includes data on the mean daily individual availability of foods and beverages in twenty-one European countries, covering various time points in each country ${ }^{(16)}$. Before being integrated in the databank, the HBS values are cleaned, managed and harmonised following standard procedures to ensure comparability between countries ${ }^{(17)}$. Food quantities available for consumption by each household member are calculated by dividing the household availability by the product of the referent time period and the mean household size, assuming equal distribution of food between household members during the survey period. Weighting factors are also incorporated, whenever necessary, to accommodate national sampling schemes.

In order to address the latency issue associated with the development of chronic diseases, data on food availability (HBS) were retrieved for the earliest of the HBS included in the DAFNE databank and, subsequently, the food supply data (FBS) used corresponded to the initial year of the HBS data collection. To increase comparability between the food groups under study, information on the HBS-derived availability of fruit juices was added to the daily fruit availability, as the FBS-derived supply data refer to the commodity level before food items are processed for further use.

To evaluate the correlation between the dietary data and mortality statistics in the participating countries, data on overall mortality, as well as on mortality from CHD and total cancer around 2004 were retrieved from the WHO 'European mortality database' (http://data.euro.who.int/hfamdb/), which provides rates adjusted to the standard European population. To control for differences in the prosperity of the participating countries, estimates made by the International Monetary Fund on national gross domestic products (GDP) in 2006 were considered. The GDP estimates, expressed in US dollars, were derived from purchasing power parity calculations to reflect differences in the relative cost of living and inflation rates of the participating countries (International Monetary Fund, World Economic Outlook Database, October 2007, for the year 2006). Information on the use of tobacco products in each country was retrieved from the WHO 'Health for all database' (http://data.euro.who.int/hfadb/) and refers to the total number of cigarettes sold/person per year in the mid1980s, or in the first year available (1990 for Germany, 1993 for the Slovak Republic and 1996 for Slovenia).

We have focused on food groups which are adequately and comparably captured by both FBS and HBS and for which there is epidemiological evidence that they can have noticeable impact on population mortality, because they are widely consumed and are believed to affect common diseases. Such foods include fruits and vegetables (including legumes) which are likely to be inversely associated with overall mortality, coronary mortality and total cancer mortality ${ }^{(18-20)}$. Fish and olive oil are also probably inversely associated with coronary mortality and thus overall mortality ${ }^{(18)}$. With respect to meat and meat products, there is strong evidence 
for a positive association with colorectal cancer, but little evidence for a major role on mortality for other forms of cancer or $\mathrm{CHD}^{(19)}$.

To evaluate the extent to which the FBS- and HBS-derived data correlate, Spearman coefficients between the supply (FBS) and the availability (HBS) of the selected foods were estimated. Partial rank correlation coefficients were estimated between overall mortality and combined fruits and vegetables (including legumes), adjusting for the countries' GDP and use of tobacco products. Subsequently, partial rank correlation coefficients were estimated between overall mortality and (in turn, in place of combined fruits and vegetables) vegetables (including legumes), fruits, fish and seafood, and olive oil. Last, the correlation coefficients between all the aforementioned variables and cause-specific mortality, notably coronary and total cancer mortality, were estimated ${ }^{(21)}$.

\section{Results}

Table 1 shows the mean daily supply (from FBS) and availability (from HBS) of major food groups and olive oil in eighteen European countries, expressed in g/person per $d$. Supply values are as a rule higher than the availability values, primarily because of several and variable losses intervening before 'supply' at population level becomes 'availability' at household level. When HBS-derived values are higher than the FBS-derived ones this may, in most instances, be attributed to contribution from own production which is not fully captured by FBS but is accounted for in the HBS data. Nevertheless, correlations between data from HBS and corresponding data from FBS are quite strong. The Spearman's correlation coefficient for vegetables (including legumes) is $+0.78\left(P<10^{-3}\right)$, for fruits $+0.76\left(P<10^{-3}\right)$, for fish and seafood $+0.69\left(P<10^{-3}\right)$ and for olive oil $+0.93\left(P<10^{-3}\right)$. With respect to meat and meat products, the Spearman's correlation coefficient is lower at +0.39
$(P=0 \cdot 08)$. Exclusion of Malta which is an outlier and has a small resident population would increase the Spearman's correlation coefficient to $+0.49(P=0.03)$.

Table 2 shows partial rank correlation coefficients of mortality rates with GDP, tobacco smoking and FBS- or HBSderived dietary variables, in eighteen European countries. The results in this Table are only indicative because of the ecological nature of the associations, the limited number of study points (eighteen) and the inability to fully control for potential confounders. Nevertheless, the data in the Table reveal the expected inverse association between GDP and mortality, adjusting for the use of tobacco products in the country and the supply (FBS) or availability (HBS) of fruits and vegetables (including legumes), major food groups that are commonly implicated in diet-disease associations. Table 2 further indicates a positive, albeit non-significant, association between tobacco smoking and the mortality indicators, after controlling for the combined fruit and vegetable supply or availability and the GDP. Vegetables (including legumes), fruits, fish and seafood, as well as olive oil also show the expected inverse associations with mortality indicators, controlling for differences in the countries' GDP and tobacco smoking.

\section{Discussion}

We have retrieved for eighteen European countries information on per person supply (from FBS) and on per person availability (from HBS) as available in the DAFNE databank, with respect to four major food groups (vegetables, including legumes; fruits; meat and meat products; fish and seafood), as well as olive oil. We have found that their Spearman's correlation coefficients are all positive and moderately high, ranging from +0.69 (for fish and seafood) to +0.93 (for olive oil), except for meat and meat products for which the correlation coefficient was somewhat lower at $+0 \cdot 39$,

Table 1. Mean daily supply (from food balance sheets, FBS) and availability (from household budget surveys, HBS) of major food groups* and olive oil in eighteen European countries ( $g /$ person per d)

\begin{tabular}{|c|c|c|c|c|c|c|c|c|c|c|}
\hline \multirow[b]{2}{*}{ Country and years of data collection } & \multicolumn{2}{|c|}{$\begin{array}{l}\text { Vegetables and } \\
\text { legumes }\end{array}$} & \multicolumn{2}{|c|}{ Fruits } & \multicolumn{2}{|c|}{$\begin{array}{l}\text { Meat and meat } \\
\text { products }\end{array}$} & \multicolumn{2}{|c|}{$\begin{array}{l}\text { Fish and } \\
\text { seafood }\end{array}$} & \multicolumn{2}{|c|}{ Olive oil } \\
\hline & FBS & HBS & FBS & HBS & FBS & HBS & FBS & HBS & FBS & HBS \\
\hline Austria (1999-2000) & $250 \cdot 9$ & $142 \cdot 3$ & $305 \cdot 6$ & $280 \cdot 0$ & $317 \cdot 1$ & $181 \cdot 8$ & $39 \cdot 6$ & $9 \cdot 3$ & $1 \cdot 3$ & $2 \cdot 9$ \\
\hline Belgium (1987-8) & $247 \cdot 0$ & $161 \cdot 4$ & $249 \cdot 2$ & $198 \cdot 7$ & $277 \cdot 3$ & $166 \cdot 4$ & $50 \cdot 7$ & $21 \cdot 0$ & 0.4 & 0.5 \\
\hline Finland (1985) & $126 \cdot 8$ & 95.9 & $168 \cdot 3$ & 184.5 & 178.6 & 139.9 & $90 \cdot 0$ & 29.5 & 0.1 & 0 \\
\hline France (1985) & $350 \cdot 3$ & $189 \cdot 1$ & 187.9 & $161 \cdot 3$ & $298 \cdot 1$ & $169 \cdot 0$ & $70 \cdot 1$ & $18 \cdot 0$ & 1.3 & $1 \cdot 2$ \\
\hline Germany (1993) & $200 \cdot 1$ & $143 \cdot 3$ & 303.8 & 301.7 & 247.0 & $132 \cdot 4$ & $39 \cdot 2$ & $21 \cdot 8$ & 0.4 & 0.7 \\
\hline Greece (1987-8) & $733 \cdot 0$ & 279.5 & $486 \cdot 3$ & 350.4 & $205 \cdot 2$ & 173.6 & $47 \cdot 0$ & 39.6 & $52 \cdot 7$ & 63.4 \\
\hline Hungary (1991) & $271 \cdot 0$ & $204 \cdot 7$ & 177.9 & $159 \cdot 1$ & $270 \cdot 0$ & $188 \cdot 1$ & $10 \cdot 9$ & 4.4 & 0 & 0 \\
\hline Italy (1990) & $486 \cdot 4$ & $208 \cdot 8$ & 353.5 & 269.2 & $245 \cdot 3$ & 159.6 & 63.0 & 41.0 & 33.7 & $42 \cdot 3$ \\
\hline Malta (1994) & 334.4 & $182 \cdot 6$ & $265 \cdot 2$ & $239 \cdot 1$ & $182 \cdot 5$ & $198 \cdot 3$ & 87.9 & 31.9 & 0.8 & 0.1 \\
\hline Norway (1986-8) & $158 \cdot 1$ & 94.5 & $294 \cdot 1$ & $163 \cdot 0$ & $152 \cdot 1$ & $121 \cdot 2$ & $120 \cdot 5$ & $54 \cdot 1$ & 0.4 & $0 \cdot 1$ \\
\hline Poland (1988) & $333 \cdot 6$ & $205 \cdot 1$ & 88.1 & $100 \cdot 2$ & $208 \cdot 4$ & 169.5 & 39.5 & $15 \cdot 3$ & 0.02 & 0 \\
\hline Portugal (1989-90) & $508 \cdot 4$ & $165 \cdot 1$ & $275 \cdot 7$ & 212.9 & $186 \cdot 2$ & $142 \cdot 9$ & $162 \cdot 2$ & 74.5 & $11 \cdot 1$ & $22 \cdot 7$ \\
\hline Republic of Ireland (1988) & $200 \cdot 4$ & $127 \cdot 7$ & $192 \cdot 3$ & $103 \cdot 2$ & 286.7 & 133.0 & 47.0 & $10 \cdot 7$ & 0.2 & 0.03 \\
\hline Slovak Republic (1997) & $235 \cdot 0$ & 124.9 & $182 \cdot 8$ & $242 \cdot 5$ & $222 \cdot 7$ & $152 \cdot 1$ & 24.4 & $13 \cdot 2$ & $0 \cdot 1$ & 0 \\
\hline Slovenia (1998) & $242 \cdot 6$ & $189 \cdot 0$ & 304.3 & 296.9 & $272 \cdot 7$ & $190 \cdot 0$ & $19 \cdot 1$ & $11 \cdot 1$ & $2 \cdot 6$ & 1.4 \\
\hline Spain (1980) & 494.8 & 234.0 & $249 \cdot 2$ & 291.4 & $200 \cdot 1$ & $187 \cdot 1$ & $90 \cdot 8$ & 74.9 & $25 \cdot 9$ & $47 \cdot 8$ \\
\hline Sweden (1989) & $178 \cdot 2$ & $100 \cdot 3$ & 258.9 & 163.5 & $168 \cdot 3$ & $111 \cdot 7$ & $82 \cdot 2$ & $31 \cdot 6$ & $0 \cdot 2$ & 0.1 \\
\hline United Kingdom (1985) & 237.3 & $160 \cdot 5$ & 179.1 & 107.5 & 208.5 & 148.9 & $50 \cdot 9$ & $19 \cdot 8$ & 0.2 & 0.2 \\
\hline
\end{tabular}

* Food groups evaluated were those that are consumed in high quantities and are classified in a comparable way in FBS and HBS. 
Table 2. Partial rank correlation coefficients $(r)$ between mortality rates and gross domestic product (GDP), tobacco smoking and food balance sheet (FBS)- or household budget survey (HBS)-derived dietary variables in eighteen European countries

\begin{tabular}{|c|c|c|c|c|c|c|c|c|c|c|c|c|}
\hline \multirow[b]{3}{*}{ Variables } & \multicolumn{4}{|c|}{ Total mortality } & \multicolumn{4}{|c|}{ Coronary mortality } & \multicolumn{4}{|c|}{ Total cancer mortality } \\
\hline & \multicolumn{2}{|c|}{ FBS } & \multicolumn{2}{|c|}{ HBS } & \multicolumn{2}{|c|}{ FBS } & \multicolumn{2}{|c|}{ HBS } & \multicolumn{2}{|c|}{ FBS } & \multicolumn{2}{|c|}{ HBS } \\
\hline & $r$ & $P$ & $r$ & $P$ & $r$ & $P$ & $r$ & $P$ & $r$ & $P$ & $r$ & $P$ \\
\hline GDP $^{*}$ & -0.58 & 0.02 & -0.53 & 0.03 & -0.48 & 0.06 & -0.18 & 0.50 & -0.25 & 0.36 & -0.19 & 0.48 \\
\hline Tobacco smoking† & +0.20 & 0.46 & +0.29 & 0.27 & +0.10 & 0.71 & +0.23 & 0.40 & +0.30 & 0.26 & +0.44 & 0.09 \\
\hline $\begin{array}{l}\text { Fruits and vegetables } \\
\text { (including legumes) } \ddagger\end{array}$ & -0.39 & 0.14 & -0.33 & 0.22 & -0.78 & $<10^{-3}$ & -0.46 & 0.07 & -0.39 & 0.13 & -0.45 & 0.08 \\
\hline \multicolumn{13}{|c|}{ Variables entered in turn, instead of fruits and vegetables§ } \\
\hline Vegetables (including legumes) & -0.47 & 0.07 & -0.49 & 0.05 & -0.76 & 0.001 & -0.76 & 0.001 & -0.39 & 0.14 & -0.17 & 0.52 \\
\hline Fruits & -0.27 & 0.32 & -0.21 & 0.44 & -0.49 & 0.05 & -0.32 & 0.23 & -0.44 & 0.09 & -0.44 & 0.09 \\
\hline Olive oil & -0.55 & 0.03 & -0.44 & 0.09 & -0.84 & $<10^{-3}$ & -0.85 & $<10^{-3}$ & -0.52 & 0.04 & -0.43 & 0.10 \\
\hline Fish and seafood & -0.59 & 0.02 & -0.47 & 0.06 & -0.53 & 0.04 & -0.59 & 0.02 & -0.71 & 0.002 & -0.63 & 0.008 \\
\hline
\end{tabular}

${ }^{*}$ Purchasing power parity-adjusted.

† Tobacco smoking expressed in number of cigarettes consumed/person per year.

$\mp$ Coefficients between mortality indices and combined fruits and vegetables (including legumes), adjusting for the countries' GDP and use of tobacco products.

$\S$ Coefficients between mortality indices and (in turn, in place of combined fruits and vegetables) vegetables (including legumes), fruits, fish and seafood, and olive oil, adjusting for the countries' GDP and use of tobacco products.

possibly because eating out is frequently focused on meat and meat products. The reasonably high correlation coefficients, also reported in previous publications ${ }^{(22)}$, provide mutual support to the adequacy of the data generated by both FBS and HBS. Thus, these two sources of data are valuable and complement each other, with superiority of one over the other being objective-specific. There is obviously scope in improving the comparability of the two systems, since combination of information may improve the approximation to the true, but not directly ascertainable, value ${ }^{(23)}$.

We have also attempted to examine whether the dietary estimates as ascertained by the two alternative sources correlate with overall mortality, coronary mortality and total cancer mortality. The epidemiological literature indicates that the intake of fruits and vegetables (including legumes) are probably, though not conclusively, inversely associated with total mortality, coronary mortality and total cancer mortality ${ }^{(18-20)}$. Fish and olive oil are likely to be inversely associated with coronary mortality and, since this mortality represents about half of the total, these foods are likely to be inversely associated with total mortality ${ }^{(18)}$. Moreover, for olive oil there is some evidence that it may be inversely related to incidence of breast cancer and colorectal cancer and, in the context of the Mediterranean diet, to total cancer mortality ${ }^{(24-26)}$ With respect to meat and meat products, there is strong evidence for a positive association with colorectal cancer, but deaths from colorectal cancer represent a small minority of all cancer deaths (less than $10 \%$ ) that are unlikely to influence an ecological association of meat with total or cancer mortality ${ }^{(19)}$.

After controlling for purchasing power parity-adjusted GDP and tobacco smoking, we found that for vegetables (including legumes), fruits, fish and seafood, as well as for olive oil both the FBS and the HBS estimates are inversely associated with all three indicated mortality indices. Although the limited number of points in the calculation of the correlation coefficients does not allow formal statistical documentation $(P$ values were in some instances higher than 0.05), the patterns support the adequacy of the two sources of information by providing a quasi-biomedical validation.
The FBS provide information on food supply at the population level in terms of the major food commodities that are assumed to be available for human consumption in the country ${ }^{(1)}$. The data refer to the early stages of the food chain and the per person supply is obtained by dividing the respective food quantity by the population partaking of it. The total population estimates, however, refer as a rule to resident population only, while non-resident population, such as tourists, illegal immigrants, refugees, etc are generally not included. This omission may therefore result in an underestimation of the total partaker population and an overestimation of the various per person food supplies. The accuracy of FBS data is further dependent on the reliability of the underlying basic statistics which vary in terms of coverage and accuracy. Although import and export data are generally accurate, in some cases there may be some trade across national boundaries that goes unrecorded. Data on own food production are collected in some countries, but this information can be substantially under-recorded where there is a thriving economy in home production. Waste and food given to pets may also be sources of error.

HBS provide information on foods and beverages available for consumption to a nationally representative sample of households. The members of the participating households are asked to record information on all foods and beverages available in the household during a reference period, including purchases, contributions from own production and food items offered to members as gifts ${ }^{(2,27)}$. The survey is implemented over a period of 1 year, with due attention to capture seasonal variation in food intake. Information on the demographic and socio-economic characteristics of the household members is also recorded, allowing analyses on the effect of socioeconomic determinants on food choices. The HBS are not primarily designed to collect nutritional information and the food data bear limitations, which need to be considered when they are used for nutritional or epidemiological purposes. In most cases, no records are collected on the type and quantity of food items and beverages consumed outside the home (at restaurants, canteens and similar establishments, for example); food losses and waste, foods given to pets, as 
well as meals offered to guests, are not consistently collected; and sex- and age-specific estimations of food consumption require the application of statistical models ${ }^{(28)}$. Despite these limitations, the HBS provide a resource for conducting a wide range of nutritional analyses and could help in highlighting issues such as (a) the dietary patterns prevailing in Europe and their sociodemographic determinants ${ }^{(13)}$; (b) time trends in the food habits of European populations ${ }^{(29,30)}$; (c) the evaluation of nutrition action plans, interventions and related strategies implemented at national or international level ${ }^{(31)}$

The present study provides some assurance about the adequacy of information provided by FBS and HBS, information that has been widely used, particularly with respect to $\mathrm{FBS}^{(7-10)}$, whereas the use of HBS is relatively more recent $^{(11,14,15,27)}$. Our findings are in line with those of previous publications in which authors comment that, in spite of the limitations of the methods, both FBS- and HBS-derived data capture the possible role for dietary factors in explaining mortality rates ${ }^{(7,10,11,14,15)}$ and others report good correlations of dietary fat (mostly saturated) with mortality from cancer at various sites ${ }^{(8,9)}$. The majority of these publications make use of one country's or a few selected countries' data to examine associations, whereas the contribution of the present study is that it combines the national FBS and HBS data of eighteen different European countries. The study has some weaknesses imposed by the nature of the data. The analyses were ecological rather than individual-based and such analyses are known to suffer from a number of biases which are particular to this study design, including the aggregation and specification biases jointly responsible for the so-called ecological fallacy ${ }^{(32)}$. The unavoidably small number of study points (the number of European countries with information for all the study variables) is another limitation. Although information on mortality was, on average, 10 years later than the information on nutritional variables, taking latency into account, the information on confounding variables was constrained by availability and comparability and was in several instances more recent. The purchasing power parity-adjusted GDP was referring to a single point estimate not adequately reflecting wellbeing and economic transformations taking place throughout the study period. Finally, there is no assurance about the comparability of cause-specific mortality statistics $^{(33)}$ or the quality of the data on confounding variables.

To summarise, in the present paper we have been able to document a relatively high correlation between per person estimates derived from FBS and HBS with respect to foods which are classified in a comparable way in both databases. We have further found evidence that vegetables (including legumes), fruits, fish and seafood, as well as olive oil are inversely associated with mortality indicators although the ecological approach and the limited number of countries with usable data do not allow robust inferences.

Individual-based food consumption surveys are indisputably superior as they are based on individuals whose socio-economic and health characteristics can be ascertained. They are, however, very demanding to undertake and difficult to replicate with uniform standards.

In the absence of regular and comparable individual-based surveys across countries, FBS and HBS are likely to remain valuable sources of information about long-term nutrition trends, their sociodemographic determinants and their likely health implications. FBS and HBS have their own strengths and weaknesses but the currently undertaken methodological review and analysis of the FBS data ${ }^{(34)}$ justifies continuous interest in the HBS system.

\section{Acknowledgements}

The DAFNE initiative has been supported through the Health Monitoring Programme of the Directorate General of Health and Consumers Protection (DG-SANCO) and the Directorate General of Research (DG-RESEARCH) of the European Commission, as well as the Hellenic Ministry of Health and Welfare and the Hellenic Health Foundation.

Thanks are due to the Statistical Offices of all countries of the DAFNE network for supplying their national HBS data and supporting documentation and for their unreserved collaboration. The institution where the work was performed is the Department of Hygiene and Epidemiology, School of Medicine, University of Athens, 75 Mikras Asias Street, Athens 115 27, Greece.

A. N. was the coordinator for the analyses in the paper and for drafting the manuscript. A. T. is the principal investigator of the European DAFNE initiative continuously since 1994. All other authors contributed the HBS data of their own countries, collaborated in rendering the HBS data comparable between countries and provided suggestions and comments for the analyses and drafting of the manuscript.

None of the authors has any conflicts of interest to declare.

\section{References}

1. Food and Agriculture Organization of the United Nations (2007) Workshop on supply utilisation accounts and food balance sheets. Food Balance Sheets: History, Sources, Concepts and Definitions. http://www.foodsec.org/tr/stat/tr_taj_02_fbs.pdf (accessed 21 February 2008).

2. Trichopoulou A (1992) Monitoring food intake in Europe: a food data bank based on household budget surveys. Eur $J$ Clin Nutr 46, Suppl. 5, S3-S8.

3. US Department of Health and Human Services Centers for Disease Control and Prevention (2008) N H A N E S - National Health and Nutrition Examination Survey home page. http:// www.cdc.gov/nchs/nhanes.htm (accessed 21 February 2008).

4. Hoare J, Henderson L, Bates CJ, et al. (2004) The National Diet and Nutrition Survey: Adults Aged 19 to 64 Years, vol. 5: summary report. London: The Stationery Office.

5. Ocké MC, Hulshof KFAM \& van Rossum CTM (2005) The Dutch national food consumption survey 2003. Methodological issues. Arch Public Health 63, 227-241.

6. Elmadfa I (2003) Austrian Nutrition Report 2003. English Summary. Vienna: Federal Ministry of Health and Women.

7. Armstrong B \& Doll R (1975) Environmental factors and cancer incidence and mortality in different countries, with special reference to dietary practices. Int J Cancer 15, 617-631.

8. Carroll KK, Braden LM, Bell JA, et al. (1986) Fat and cancer. Cancer 58, Suppl. 8, 1818-1825.

9. Serra-Majem L, La Vecchia C, Ribas-Barba L, et al. (1993) Changes in diet and mortality from selected cancers in southern Mediterranean countries, 1960-1989. Eur J Clin Nutr 47, Suppl. 1, S25-S34.

10. Trichopoulos D \& Lagiou P (2004) Mediterranean diet and overall mortality differences in the European Union. Public Health Nutr 7, 949-951. 
11. Prieto-Ramos F, Serra-Majem L, La Vecchia C, et al. (1996) Mortality trends and past and current dietary factors of breast cancer in Spain. Eur J Epidemiol 12, 141-148.

12. Trichopoulou A, Naska A, Costacou T, et al. (2002) Disparities in food habits across Europe. Proc Nutr Soc 61, 553-558.

13. Naska A, Fouskakis D, Oikonomou E, et al. (2006) Dietary patterns and their socio-demographic determinants in ten European countries. Data from the DAFNE databank. Eur J Clin Nutr 60, $181-190$.

14. Lagiou P, Trichopoulou A, Henderickx HK, et al. (1999) Household budget survey nutritional data in relation to mortality from coronary heart disease, colorectal cancer and female breast cancer in European countries. DAFNE I and II projects of the European Commission. Data Food Networking. Eur J Clin Nutr 53, 328-332.

15. Rodrigues SSP, Trichopoulou A \& de Almeida MDV (2008) Household diet quality in relation to mortality in Portuguese regions: an ecological study. J Public Health 16, 43-51.

16. Trichopoulou A, Naska A \& Oikonomou E (2005) The DAFNE databank: the past and the future of monitoring the dietary habits of Europeans. J Public Health 13, 69-73.

17. Lagiou P \& Trichopoulou A (2001) DAFNE contributors. DAta Food NEtworking The DAFNE initiative: the methodology for assessing dietary patterns across Europe using household budget survey data. Public Health Nutr 4, 1135-1141.

18. Willett WC (1998) Nutritional Epidemiology, 2nd ed. New York: Oxford University Press.

19. World Cancer Research Fund \& American Institute for Cancer Research (2007) Food, Nutrition and Physical Activity, and the Prevention of Cancer: a Global Perspective. Washington, DC: American Institute for Cancer Research.

20. Benetou V, Orfanos P, Lagiou P, et al. (2008) Vegetables and fruits in relation to cancer risk: evidence from the Greek EPIC cohort study. Cancer Epidemiol Biomarkers Prev 17, 387-392.

21. Altman GD (1991) Practical Statistics for Medical Research. London: Chapman and Hall.

22. Rodrigues SSP, Lopes C, Naska A, et al. (2007) Comparison of national food supply, household food availability and individual food consumption data in Portugal. J Public Health 15, 447-455.
23. Marshall J (1989) The use of multiple reports in epidemiological studies. Stat Med 8, 1041-1050.

24. Trichopoulou A (1995) Olive oil and breast cancer. Cancer Causes Control 6, 475-476.

25. Braga C, La Vecchia C, Franceschi S, et al. (1998) Olive oil, other seasoning fats, and the risk of colorectal carcinoma. Cancer 82, 448-453.

26. Trichopoulou A, Costacou T, Bamia C, et al. (2003) Adherence to a Mediterranean diet and survival in a Greek population. $N$ Engl J Med 348, 2599-2608.

27. Naska A, Vasdekis VG \& Trichopoulou A (2001) A preliminary assessment of the use of household budget survey data for the prediction of individual food consumption. Public Health Nutr 4, 1159-1165

28. Vasdekis VG, Stylianou S \& Naska A (2001) Estimation of age and gender-specific food availability from household budget survey data. Public Health Nutr 4, 1149-1151.

29. European Commission Directorate General for Health and Consumers (2003) Network for the Pan-European Food Data Bank based on Household Budget Surveys. The DAFNE III project. http://ec.europa.eu/health/ph_projects/1999/monitoring/monitoring_project_1999_full_en.htm\#1 (accessed 21 February 2008).

30. European Commission Directorate General for Health and Consumers (2005) Network for the Pan-European Food Data Bank based on Household Budget Surveys. The DAFNE IV project. http://ec.europa.eu/health/ph_projects/2002/monitoring/ monitoring_2002_04_en.htm (accessed 21 February 2008).

31. Naska A, Vasdekis VG, Trichopoulou A, et al. (2000) Fruit and vegetable availability among ten European countries: how does it compare with the 'five-a-day' recommendation? Br J Nutr $\mathbf{8 4}$, $549-556$

32. Morgenstern H (1982) Uses of ecologic analysis in epidemiologic research. Am J Public Health 72, 1336-1344.

33. Murray CJ \& Lopez AD (1997) Mortality by cause for eight regions of the world: Global Burden of Disease Study. Lancet 349, 1269-1276.

34. Food and Agriculture Organization of the United Nations (2008) FAOSTAT. http://faostat.fao.org/site/291/default.aspx (accessed 21 February 2008). 